\title{
BMJ Open Interpregnancy weight changes and impact on pregnancy outcome in a cohort of women with a macrosomic first delivery: a prospective longitudinal study
}

\author{
David A Crosby, ${ }^{1,2}$ Jennifer M Walsh, ${ }^{1,2}$ Ricardo Segurado, ${ }^{3}$ \\ Fionnuala M McAuliffe ${ }^{1,2}$
}

To cite: Crosby DA,

Walsh JM, Segurado R, et al. Interpregnancy weight changes and impact on pregnancy outcome in a cohort of women with a macrosomic first delivery: a prospective longitudinal study. BMJ Open 2017;7:e016193. doi:10.1136/ bmjopen-2017-016193

- Prepublication history and additional material are available. To view these files please visit the journal online (http://dx.doi.org/ 10.1136/ bmjopen-2017-016193)

Received 4 February 2017 Revised 10 March 2017 Accepted 16 March 2017

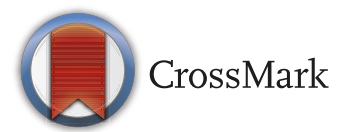

${ }^{1}$ Department of Obstetrics and Gynaecology, National Maternity Hospital, Dublin, Ireland

${ }^{2}$ UCD Perinatal Research Centre, School of Medicine, University College Dublin, Dublin, Ireland ${ }^{3}$ CSTAR, School of Public Health, Physiotherapy and Population Science, University College Dublin, Dublin, Ireland

Correspondence to Prof. Fionnuala M McAuliffe; fionnuala.mcauliffe@ucd.ie

\section{ABSTRACT}

Objective To determine the median interpregnancy maternal weight change between first and second pregnancies, and second and third pregnancies and to assess the impact of this weight change on pregnancy outcome in a cohort of women with a macrosomic first delivery.

Study design Prospective longitudinal study conducted over three pregnancies from 2007 to 2015.

Setting Tertiary referral maternity hospital, Dublin, Ireland. Participants Women were recruited if their first baby weighed $>4.0 \mathrm{~kg}$.

Methods The pregnancy outcomes in the second and third pregnancies were analysed separately. Data were also analysed for both interpregnancy intervals comparing outcomes for those who gained any weight, or more weight than the median, with those who did not. Main outcome measures Recurrent fetal macrosomia $\geq 4.0 \mathrm{~kg}$ and gestational diabetes mellitus.

Results There were 280 women who delivered a third baby between 2011 and 2015. There were no differences in pregnancy outcomes for the second pregnancy in women who gained interpregnancy weight compared with those who did not and those who gained more interpregnancy weight than the median compared with those who did not. There was a statistically significant increase in birth weight $\geq 4.0 \mathrm{~kg}$ ( $54.0 \%$ vs $39.6 \% \mathrm{p}=0.03$ ) in those women who gained any weight between the second and third pregnancies. In those women who gained more interpregnancy weight than the median $(1.70 \mathrm{~kg})$ between a second and third pregnancy, there was a significant increase in the rate of gestational diabetes (6.5\% vs $1.4 \%, p=0.03$ ).

Conclusions This longitudinal study demonstrates that within this cohort maternal interpregnancy weight change between a second and third pregnancy is associated with an increase in birth weight $\geq 4.0 \mathrm{~kg}$. Additionally, a gain of more weight than the median $(1.70 \mathrm{~kg})$ is associated with a higher rate of gestational diabetes.

\section{INTRODUCTION}

Fetal macrosomia is a common obstetric problem, affecting up to $20 \%$ of babies born
Strengths and limitations of this study

- Maternal weight and height were measured at booking visit in each pregnancy $<18$ weeks gestation and body mass index calculated accurately, rather than relying on maternal self-reporting.

- Uniform cohort: they delivered a first baby weight $>4.0 \mathrm{~kg}$ and they did not have gestational diabetes or hypertensive disorders in the first pregnancy.

- Data were prospectively collected by an investigator and accurately recorded into an anonymised computerised database.

- Longitudinal study, which has advantages over a cross-sectional study.

- A potential limitation of this study is that we do not have data on women who attended elsewhere for subsequent antenatal care.

at term. ${ }^{12}$ The incidence varies according to the birth weight cut-offs employed as it is varyingly defined as an absolute birth weight $>4000 \mathrm{~g}, 4500 \mathrm{~g}$ or as a customised birth weight centile of greater than the 90th, 95th or 97 th percentile for the infant's gestational age. $^{3}$ It is associated with adverse obstetric maternal outcomes and neonatal outcomes, such as hypoglycaemia, hypomagnesaemia and hyperbilirubinaemia. ${ }^{4-6}$ Furthermore, infants with increased weight and body mass index (BMI) are more likely to be obese in childhood, ${ }^{7}$ and this is contributing to the burden of obesity on global health. ${ }^{3}$ Women with a history of birth of a macrosomic infant are at significantly increased risk of delivering another macrosomic infant in a subsequent pregnancy, ${ }^{8}$ and the risk increases further with a history of two macrosomic infants. ${ }^{9}$ Maternal weight gain during pregnancy influences fetal birth weight, ${ }^{10}$ and excessive gestational weight gain is strongly associated 
with fetal macrosomia. ${ }^{11}$ Interventions to limit gestational weight gain are, however, limited at best, perhaps due to perceived concerns regarding dietary and lifestyle changes during the prenatal period. ${ }^{12}$

Less attention has been traditionally focused on weight changes, and weight gain in particular, during the interval between pregnancies. Interpregnancy weight gain has, however, been associated with gestational hypertensive disease, gestational diabetes (GDM), caesarean section (CS), fetal macrosomia and even stillbirth. ${ }^{13-16}$ The postpartum and interval pregnancy time period therefore may represent a specific opportunity for targeted public health education, in women from every BMI category to prevent movement into a higher BMI category. ${ }^{17}$ To date, there are paucity of published longitudinal data on interpregnancy weight changes and the impact on both maternal and neonatal outcomes.

The objective of this longitudinal study was to determine the median interpregnancy maternal weight change between first and second pregnancies, and second and third pregnancies and to assess the impact of this weight change on pregnancy outcome in a cohort of women with a macrosomic first delivery.

\section{METHODS}

This is a prospective longitudinal study over three pregnancies. Women were initially recruited to the Randomised cOntrol trial of LOw glycaemic index diet versus no dietary intervention to prevent recurrence of fetal macrosomia (ROLO) study if their first baby weighed $>4.0 \mathrm{~kg}$. Recruitment to the randomised trial, with institutional ethical approval and maternal written consent, commenced in January 2007 and completed in January 2011. In total, 800 secundigravida women without diabetes, who had previously given birth to a macrosomic baby $(>4.0 \mathrm{~kg}$ ) and were therefore at increased risk of delivering another macrosomic infant, ${ }^{9}$ were randomised to receive either low glycaemic index (GI) dietary advice or usual antenatal care. Detailed methodology and results of the ROLO study have previously been published. ${ }^{818}$ In brief, the low GI diet did not impact on birth weight, but maternal benefits were noted in terms of less gestational weight gain $(12.2 \mathrm{kgvs}$ $13.7 \mathrm{~kg}, \mathrm{p}<0.05)$ and less glucose intolerance (21\% vs $28 \%$, $\mathrm{p}<0.05)$. Low GI dietary advice was given at week 14 of pregnancy and the women in the intervention group were found to have a significantly reduced GI and glycaemic load following the intervention.

Mothers were then followed prospectively and data collated and anonymised on 280 women who delivered two further babies up to 2015. Weight and height were measured accurately at first presentation prior to 18 weeks gestation in each pregnancy and BMI calculated. Relevant descriptive statistics were obtained for the study population.

The pregnancy outcomes in the second and third pregnancies were analysed separately with respect to the previous interpregnancy period using absolute weight change. Data were also analysed for both interpregnancy intervals comparing outcomes for those who gained any weight, or those who gained more weight than the median with those who did not, which may be a more convenient definition for clinical practice. The pregnancy outcomes analysed were CS, GDM, recurrent fetal macrosomia, gestational hypertensive disease, neonatal intensive care unit (NICU) admission and stillbirth. We used the MannWhitney $\mathrm{U}$ test to evaluate differences in continuous variables between the groups or over time and $\chi^{2}$ tests to compare categorical variables between groups. We set statistical significance at $\mathrm{p}<0.05$ and used SPSS V.23.0 for statistical analysis.

\section{RESULTS}

Of the initial 800 women recruited to the ROLO study, 280 $(35.0 \%)$ women delivered a third baby between 2011 and 2015. Of these, the median maternal weight in the first pregnancy was $68.8 \mathrm{~kg}$ (IQR 62.0-78.5) and the median BMI was $24.9 \mathrm{~kg} / \mathrm{m}^{2}$ (IQR 22.7-27.3). In total, $11.4 \%$ $(n=32)$ of the cohort were obese in the first trimester of the first pregnancy. Table 1 details the demographic data for the cohort in the first trimester of the first, second and third pregnancies, respectively.

Overall, $72.9 \%(\mathrm{n}=204)$ gained weight between the first and second pregnancy within a median interpregnancy interval of 24 months (IQR 23-35) and the overall median weight change was $2.60 \mathrm{~kg}$ (IQR -0.28 to 3.28 ). $67.5 \%$ $(\mathrm{n}=189)$ gained weight between the second and third pregnancy within a median interpregnancy interval of 36.0 months (IQR 24-48), and the overall median weight change was $1.70 \mathrm{~kg}$ (IQR -0.68 to 4.58 ). This resulted in

Table 1 Demographics of the cohort at in the first trimester of the first, second and third pregnancies, respectively $(n=280)$

\begin{tabular}{llll}
\hline & Pregnancy 1 & Pregnancy 2 & Pregnancy 3 \\
\hline Maternal age (years) & $29.0(23.9-32.0)$ & $31.8(29.0-34.5)$ & $34.8(31.6-37.4)$ \\
Maternal weight $(\mathrm{kg})$ & $68.8(62.0-78.5)$ & $71.4(63.6-81.1)$ & $73.1(65.1-84.5)$ \\
Body mass index $\left(\mathrm{kg} / \mathrm{m}^{2}\right)$ & $24.9(22.7-27.3)$ & $25.7(23.4-28.8)$ & $26.0(23.6-29.3)$ \\
Birth weight $(\mathrm{kg})$ & $4.2(4.07-4.33)$ & $4.1(3.74-4.35)$ & $4.0(3.68-4.36)$ \\
Gestational age (days) & $288(282-292)$ & $283(277-288)$ & $280(273-287)$ \\
Obese $\left(\geq 30 \mathrm{~kg} / \mathrm{m}^{2}\right)$ & $11.4 \%(\mathrm{n}=32)$ & $20.0 \%(\mathrm{n}=56)$ & $22.1 \%(\mathrm{n}=62)$ \\
\hline
\end{tabular}

All values are median with interquartile ranges (25th and 75th) in hypotheses, except for obesity (demonstrated in absolute numbers and percentages). Maternal weight and body mass index were calculated at $\leq 18$ weeks gestation. 
Table 2 Pregnancy outcomes for the third pregnancy based on those who gained interpregnancy weight compared with those who did not and those who gained more interpregnancy weight than the median compared with those who did not

\begin{tabular}{|c|c|c|c|}
\hline & $\begin{array}{l}\text { Gained interpregnancy weight } \\
(\mathrm{n}=189)\end{array}$ & $\begin{array}{l}\text { Did not gain interpregnancy weight } \\
(\mathrm{n}=91)\end{array}$ & $p$ Value \\
\hline CS overall & $41(21.7 \%)$ & $21(23.1 \%)$ & NS \\
\hline GDM & $9(4.8 \%)$ & $2(2.2 \%)$ & NS \\
\hline$B W \geq 4$ kg & $102(54.0 \%)$ & $36(39.6 \%)$ & 0.03 \\
\hline Hypertensive disease & $5(2.6 \%)$ & $2(2.2 \%)$ & NS \\
\hline NICU & $4(2.1 \%)$ & $2(2.2 \%)$ & NS \\
\hline \multirow[t]{2}{*}{ Stillbirth } & $1(0.5 \%)$ & $1(1.1 \%)$ & NS \\
\hline & $\begin{array}{l}\text { Gained }>1.70 \mathrm{~kg} \text { interpregnancy } \\
\text { weight }(n=139)\end{array}$ & $\begin{array}{l}\text { Gained } \leq 1.70 \mathrm{~kg} \text { interpregnancy weight } \\
(n=141)\end{array}$ & \\
\hline CS overall & $28(20.1 \%)$ & $34(24.1 \%)$ & NS \\
\hline GDM & $9(6.5 \%)$ & $2(1.4 \%)$ & 0.03 \\
\hline$B W \geq 4 \mathrm{~kg}$ & 75 (54.0\%) & $63(44.7 \%)$ & NS \\
\hline Hypertensive disease & $4(2.9 \%)$ & $3(2.1 \%)$ & NS \\
\hline $\mathrm{NICU}$ & $4(2.9 \%)$ & $2(1.4 \%)$ & NS \\
\hline Stillbirth & $0(0 \%)$ & 2 (1.4\%) & NS \\
\hline
\end{tabular}

BW, body weight; CS, caesarean section; GDM, gestational diabetes; NICU, neonatal intensive care unit; NS, not significant.

a median weight gain from first to third pregnancy of $4.30 \mathrm{~kg}$ (IQR 0.40-7.86). Overall the rate of obesity rose from $11.4 \%$ in first pregnancy to $22.1 \%$ by the beginning of the third pregnancy.

There were no differences in pregnancy outcomes for the second pregnancy (gestational hypertensive disease, GDM, CS, recurrent fetal macrosomia $\geq 4 \mathrm{~kg}$, NICU admission and stillbirth) in women who gained interpregnancy weight compared with those who did not and those who gained more interpregnancy weight than the median compared with those who did not.

There was a statistically significant increase in birth weights $\geq 4.0 \mathrm{~kg}(54.0 \%$ vs $39.6 \%, \mathrm{p}=0.03)$ in those women who gained weight between the second and third pregnancies. In those women who gained more interpregnancy weight than the median $(1.70 \mathrm{~kg})$ between a second and third pregnancy, there was a significant increase in the rate of gestational diabetes $(6.5 \%$ vs $1.4 \%, \mathrm{p}=0.03)$. There were no differences in gestational hypertensive disease, CS, NICU admission and stillbirth (table 2).
To examine the effect of cumulative weight gain over both interpregnancy intervals, and to control for the effect of maternal age and BMI $<18$ weeks gestation in the index pregnancy on the above results, logistic regression models to predict a birth weight $\geq 4.0 \mathrm{~kg}$ were run. Weight gain between the first and second, second and third and overall between first and third pregnancies had broadly similar effects, with a 2-3\% higher odds of a high birth weight per kilogram gain, which increased to $3-5 \%$ when adjusting for maternal age and BMI. Statistical significance was marginal, but present for weight gain in the earlier interval and between first and third pregnancies (table 3).

\section{DISCUSSION}

\section{Main findings}

This longitudinal study found that women who delivered a macrosomic infant $\geq 4.0 \mathrm{~kg}$ in their first pregnancy without gestational diabetes gained a median of $2.60 \mathrm{~kg}$ between a first and second pregnancy and a median of

Table 3 Effect of weight gain on odds of birth weight $\geq 4 \mathrm{~kg}$ unadjusted and adjusted for maternal age and body mass index (BMI) calculated at $<18$ weeks gestation in the index pregnancy

\begin{tabular}{|c|c|c|c|c|c|c|}
\hline & \multicolumn{3}{|c|}{ Unadjusted } & \multicolumn{3}{|c|}{ Adjusted for maternal age and BMI } \\
\hline & OR & $95 \% \mathrm{Cl}$ & p Value & OR & $95 \% \mathrm{Cl}$ & p Value \\
\hline $\begin{array}{l}\text { Weight gain from } \\
\text { pregnancy } 1 \text { to } 2\end{array}$ & 1.03 & 0.99 to 1.07 & 0.169 & 1.05 & 1.01 to 1.10 & 0.024 \\
\hline $\begin{array}{l}\text { Weight gain from } \\
\text { pregnancy } 2 \text { to } 3\end{array}$ & 1.02 & 0.98 to 1.06 & 0.243 & 1.03 & 0.99 to 1.08 & 0.107 \\
\hline $\begin{array}{l}\text { Weight gain from } \\
\text { pregnancy } 1 \text { to } 3\end{array}$ & 1.03 & 1.00 to 1.06 & 0.093 & 1.04 & 1.01 to 1.08 & 0.013 \\
\hline
\end{tabular}


$1.70 \mathrm{~kg}$ between a second and third pregnancy, resulting in a median $4.30 \mathrm{~kg}$ weight gain from first to third pregnancy. This resulted in increase in obesity rates from $11.4 \%$ in first pregnancy to $22.1 \%$ in third pregnancy, highlighting the central role pregnancy has in weight gain across the life course. The interpregnancy weight gain between first and second pregnancies did not appear to impact on pregnancy outcome; however, interpregnancy weight gain between second and third pregnancies was associated with an increased rate of recurrent fetal macrosomia $\geq 4.0 \mathrm{~kg}$. For each kilogram increase in interpregnancy weight, the odds of giving birth to an infant of $\geq 4.0 \mathrm{~kg}$ increased. Additionally, those with a weight gain of more than the median $(\geq 1.70 \mathrm{~kg})$ between second and third pregnancies was associated with increased incidence of GDM.

\section{Interpretation}

One possible explanation for the lack of associations in second pregnancy may arise due to the Hawthorne effect of trial participation in both the intervention and control arms.

Another more likely hypothesis could be that weight gain may be cumulative. The median weights at booking visit in the first, second and third pregnancies were 68.8, 71.4 and $73.1 \mathrm{~kg}$, respectively. Is weight gain cumulative so that it is only over a certain level that effects on birth weight and GDM are noted? There are a paucity of longitudinal studies on postpartum weight changes because these studies are challenging to conduct. ${ }^{19}$ This longitudinal study adds to the evidence that interpregnancy weight gain causes GDM and macrosomic babies. Many studies relating to interpregnancy weight changes are cross-sectional and retrospective in nature. Furthermore, many of these studies use self-reported maternal weight, which can be unreliable and leads to BMI miscategorisation. ${ }^{20}$ High postpartum weight retention is an important contributor to long-term maternal obesity, which has detrimental effects on long-term maternal health. ${ }^{21}$

\section{Strengths and limitations in relation to other studies}

Bogaerts $e t$ al found that in a population of 7897 women in Belgium, there was an increase rate of GDM (adjusted OR (aOR) 2.25, 95\% CI 1.33 to 3.78, $\mathrm{p}=0.002$ ) in those who had interpregnancy weight retention of $\geq 2$ BMI units. However, this study used self-reported prepregnancy weight and no prior information on hypertension and GDM available. ${ }^{15}$ A large Swedish retrospective epidemiological study of 151025 women who had their first two consecutive births between 1992 and 2001 found that those who gained $\geq 3$ BMI units between pregnancies compared with those women whose BMI changed between -1.0 and 0.9 units had an aOR of GDM of 2.09 $(1.68-2.61) .{ }^{13}$ Wallace $e t a t^{22}$ conducted a retrospective cohort study of 12740 women in Aberdeen, Scotland, who delivered their first and second children between 1986 and 2007. Weight gain of $>3$ BMI units was associated with an increase in large for gestational age infants. Jain $e t a l^{23}$ analysed a population-based historical cohort of 10444 obese women in Missouri who delivered their first infant between 1998 and 2005. Interpregnancy weight gain was associated with an increased risk of an Large for gestational age (LGA) infant (aOR 1.37, 95\% CI 1.21 to 1.54 ).

Our study is a prospective longitudinal study illustrating that interpregnancy weight gain is associated with recurrent fetal macrosomia in a unique population of women who delivered a macrosomic baby $\geq 4.0 \mathrm{~kg}$ in their index pregnancy, and that interpregnancy weight gain of greater than the median is associated with an increased rate of GDM.

The interpregnancy interval is an important time for diet and lifestyle intervention in women who have delivered a macrosomic infant in their first pregnancy in the prevention of recurrent macrosomia and the development of GDM.

\section{STRENGTHS AND LIMITATIONS}

This longitudinal study has strengths. Maternal weight and height were measured at booking visit in each pregnancy $<18$ weeks gestation and BMI calculated accurately, rather than relying on maternal self-reporting. Furthermore, this cohort of women was uniform in that they delivered a first baby weight $>4.0 \mathrm{~kg}$ and they did not have GDM or hypertensive disorders in the first pregnancy. Data were prospectively collected by an investigator and accurately recorded into an anonymised computerised database.

A potential limitation of this study is that we do not have data on women who attended elsewhere for subsequent antenatal care. Another potential limitation is that the interpregnancy interval varied between subjects within this study. Finally, this study applies to women who delivered a first baby $>4 \mathrm{~kg}$, which applies to approximately $15 \%$ of our overall primiparous population.

\section{CONCLUSIONS}

This longitudinal study demonstrates that within this cohort maternal interpregnancy weight change between a second and third pregnancy is associated with an increase in birth weight $\geq 4.0 \mathrm{~kg}$. Additionally, a gain of more weight than the median $(1.70 \mathrm{~kg})$ is associated with a higher rate of gestational diabetes. It is important to identify ways for women to maintain a normal weight and BMI throughout her life, particularly between pregnancies. Obstetricians should consider postnatal advice on interval pregnancy weight gain in order to reduce rates of macrosomia and gestational diabetes in future pregnancy in at-risk women.

Acknowledgements HRB Centre for Diet and Health Research. This work was presented at the RCOG World Congress 2016, 20-22 June 2016, ICC Birmingham, UK, and the abstract was published in the British Journal of Obstetrics and Gynaecology in June 2016. ${ }^{24}$

Contributors DAC collected data, performed the analysis and wrote the manuscript. JMW contributed to the study design and manuscript preparation. RS performed analysis. FMMcA conceived and designed the study. All of the authors reviewed and revised the final version of the manuscript. FMMcA is the guarantor. 
Competing interests None declared.

Ethics approval National Maternity Hospital Ethics Committee, Dublin.

Provenance and peer review Not commissioned; externally peer reviewed.

Data sharing statement Not applicable.

Open Access This is an Open Access article distributed in accordance with the Creative Commons Attribution Non Commercial (CC BY-NC 4.0) license, which permits others to distribute, remix, adapt, build upon this work non-commercially, and license their derivative works on different terms, provided the original work is properly cited and the use is non-commercial. See: http://creativecommons.org/ licenses/by-nc/4.0/

(c) Article author(s) (or their employer(s) unless otherwise stated in the text of the article) 2017. All rights reserved. No commercial use is permitted unless otherwise expressly granted.

\section{REFERENCES}

1. Ørskou J, Kesmodel U, Henriksen TB, et al. An increasing proportion of infants weigh more than 4000 grams at birth. Acta Obstet Gynecol Scand 2001:80:931-6.

2. National Maternity Hospital Clinical Report for the year 2014.

3. Walsh JM, McAuliffe FM. Prediction and prevention of the macrosomic fetus. Eur J Obstet Gynecol Reprod Biol 2012;162:125-30.

4. Boulet SL, Alexander GR, Salihu HM, et al. Macrosomic births in the united states: determinants, outcomes, and proposed grades of risk. Am J Obstet Gynecol 2003;188:1372-8.

5. Nold JL, Georgieff MK. Infants of diabetic mothers. Pediatr Clin North Am 2004;51:619-37.

6. Weissmann-Brenner A, Simchen MJ, Zilberberg E, et al. Materna and neonatal outcomes of large for gestational age pregnancies. Acta Obstet Gynecol Scand 2012;91:844-9.

7. Boney CM, Verma A, Tucker R, et al. Metabolic syndrome in childhood: association with birth weight, maternal obesity, and gestational diabetes mellitus. Pediatrics 2005;115:e290-e296.

8. Walsh JM, McGowan CA, Mahony R, et al. Low glycaemic index diet in pregnancy to prevent macrosomia (ROLO study): randomised control trial. BMJ 2012;345:e5605.

9. Walsh CA, Mahony RT, Foley ME, et al. Recurrence of fetal macrosomia in non-diabetic pregnancies. J Obstet Gynaecol 2007;27:374-8.
10. Abrams BF, Laros RK. Prepregnancy weight, weight gain, and birth weight. Am J Obstet Gynecol 1986:154:503-9.

11. Godoy AC, Nascimento SL, Surita FG. A systematic review and meta-analysis of gestational weight gain recommendations and related outcomes in Brazil. Clinics 2015;70:758-64.

12. Sagedal LR, Øverby NC, Bere E, et al. Lifestyle intervention to limit gestational weight gain: the norwegian fit for delivery randomised controlled trial. Bjog 2017;124:97-109.

13. Villamor E, Cnattingius S. Interpregnancy weight change and risk of adverse pregnancy outcomes: a population-based study. Lancet 2006;368:1164-70.

14. Paramsothy $P$, Lin YS, Kernic MA, et al. Interpregnancy weight gain and cesarean delivery risk in women with a history of gestational diabetes. Obstet Gynecol 2009;113:817-23.

15. Bogaerts A, Van den Bergh BR, Ameye L, et al. Interpregnancy weight change and risk for adverse perinatal outcome. Obstet Gynecol 2013;122:999-1009.

16. Cnattingius $\mathrm{S}$, Villamor $\mathrm{E}$. Weight change between successive pregnancies and risks of stillbirth and infant mortality: a nationwide cohort study. Lancet 2016:387:558-65.

17. Walsh JM, Mahony RM, Canty $G$, et al. Identification of those most likely to benefit from a low-glycaemic index dietary intervention in pregnancy. Br J Nutr 2014;112:583-9.

18. Walsh JM, McGowan CA, Mahony R, et al. Low glycaemic index diet in pregnancy to prevent macrosomia (ROLO study): randomised control trial. BMJ 2012;345:e5605.

19. O'Higgins AC, Doolan A, Mullaney L, et al. The relationship between gestational weight gain and fetal growth: time to take stock? J Perinat Med 2013;21:1-7.

20. Turner MJ. The measurement of maternal obesity: can we do better? Clin Obes 2011;1:127-9.

21. Gunderson EP. Childbearing and obesity in women: weight before, during, and after pregnancy. Obstet Gynecol Clin North Am 2009;36:317-32.

22. Wallace JM, Bhattacharya S, Campbell DM, et al. Inter-pregnancy weight change impacts placental weight and is associated with the risk of adverse pregnancy outcomes in the second pregnancy. BMC Pregnancy Childbirth 2014;14:40.

23. Jain AP, Gavard JA, Rice JJ, et al. The impact of interpregnancy weight change on birthweight in obese women. Am J Obstet Gynecol 2013;208:205.e1-205.e7.

24. Nakamura A, Osonoi T, Terauchi Y. Relationship between urinary sodium excretion and pioglitazone-induced edema. J Diabetes Investig 2010;1:208-11. 